\title{
Emergency angiography for trauma patients and potential association with acute kidney injury
}

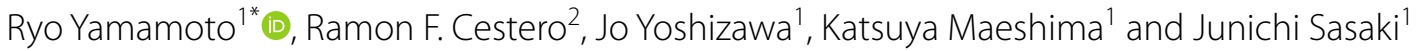

\begin{abstract}
Background: Angiography has been conducted as a hemostatic procedure for trauma patients. While several complications, such as tissue necrosis after embolization, have been reported, little is known regarding subsequent acute kidney injury (AKI) due to contrast media. To elucidate whether emergency angiography would introduce kidney dysfunction in trauma victims, we compared the incidence of AKI between patients who underwent emergency angiography and those who did not.
\end{abstract}

Methods: A retrospective cohort study was conducted using a nationwide trauma database (2004-2019), and adult trauma patients were included. The indication of emergency angiography was determined by both trauma surgeons and radiologists, and AKI was diagnosed by treating physicians based on a rise in serum creatinine and/or fall in urine output according to any published standard criteria. Incidence of AKI was compared between patients who underwent emergency angiography and those who did not. Propensity score matching was conducted to adjust baseline characteristics including age, comorbidities, mechanism of injury, vital signs on admission, Injury Severity Scale (ISS), degree of traumatic kidney injury, surgical procedures, and surgery on the kidney, such as nephrectomy and nephrorrhaphy.

Results: Among 230,776 patients eligible for the study, 14,180 underwent emergency angiography. The abdomen/ pelvis was major site for angiography (10,624 [83.5\%]). Embolization was performed in 5,541 (43.5\%). Propensity score matching selected 12,724 pairs of severely injured patients (median age, 59; median ISS, 25). While the incidence of AKI was rare, it was higher among patients who underwent emergency angiography than in those who did not (140 $[1.1 \%]$ vs. $67[0.5 \%]$; odds ratio $=2.10[1.57-2.82] ; p<0.01)$. The association between emergency angiography and subsequent AKI was observed regardless of vasopressor usage or injury severity in subgroup analyses.

Conclusions: Emergency angiography in trauma patients was probably associated with increased incidence of AKI. The results should be validated in future studies.

Keywords: Angiography, Embolization, Hemostasis, Acute kidney injury

\footnotetext{
*Correspondence: ryo.yamamoto@gmail.com

${ }^{1}$ Trauma Service/Department of Emergency and Critical Care Medicine, Keio University School of Medicine, 35 Shinanomachi, Shinjuku, Tokyo 160-8582, Japan

Full list of author information is available at the end of the article
}

\begin{abstract}
Background
Angiography has been conducted as a hemostatic or diagnostic procedure for trauma patients for several decades, and indications for angiography after injury continue to expand $[1,2]$. While surgery is the standard treatment for patients with bleeding, angiography with embolization to control arterial hemorrhage has been performed as a less invasive procedure $[1,3,4]$. Notably, the success rate of
\end{abstract} original author(s) and the source, provide a link to the Creative Commons licence, and indicate if changes were made. The images or other third party material in this article are included in the article's Creative Commons licence, unless indicated otherwise in a credit line to the material. If material is not included in the article's Creative Commons licence and your intended use is not permitted by statutory regulation or exceeds the permitted use, you will need to obtain permission directly from the copyright holder. To view a copy of this licence, visit http://creativecommons.org/licenses/by/4.0/. The Creative Commons Public Domain Dedication waiver (http://creativecommons.org/publicdomain/zero/1.0/) applies to the data made available in this article, unless otherwise stated in a credit line to the data. 
non-operative management for patients with high-grade splenic injury has been reported to be improved to $95 \%$ after emergency angiography with embolization $[5,6]$.

While several complications of angiography including tissue necrosis, re-bleeding, and vascular injury $[7,8]$ have been reported, little is known regarding subsequent kidney injury due to contrast media that is used in angiography for trauma victims. Acute kidney injury (AKI) following intravascular administration of contrast media is defined by several terms such as contrast-induced nephropathy (CIN), contrast-induced AKI (CI-AKI), or post-contrast AKI (PC-AKI) $[9,10]$, and nearly $10 \%$ of patients who were given considerable amount of contrast media in percutaneous coronary angiography were found to develop PC-AKI [11]. Conversely, a recent systematic review identified that a relatively small amount of contrast media, such as the amount administered in a contrast-enhanced CT scan, was not associated with newly developed AKI unless baseline kidney function was severely compromised [12]. Since the dosage of contrast media administered during emergency angiography for trauma patients is often higher than the amount given for a CT with contrast [13], risks of angiography on kidney function exist, and this potential effect has not been extensively examined among severely injured patients. It should be also emphasized that some trauma patients who undergo angiography are likely at higher risk for AKI due to hemodynamic instability and direct traumatic insult to the kidney $[14,15]$.

Accordingly, to eventually ascertain whether emergency angiography might independently introduce subsequent AKI among trauma patients, we used a nationwide trauma database to compare the incidence of AKI between patients who underwent emergency angiography and those who did not. We hypothesized that emergency angiography would be independently associated with higher incidence of AKI in severely injured trauma patients.

\section{Methods}

\section{Study design and setting}

We conducted a retrospective cohort study using data from the Japan Trauma Data Bank (JTDB). The JTDB was established as a Japanese nationwide trauma registry in 2003, representing $>250$ participating hospitals and tertiary care centers. Before initiating the study, all collaborating hospitals obtained individual local institutional review board approval for conducting research with human subjects [16].

Current practice in Japan recommends consideration for emergency angiography in hemodynamically stable trauma patients who have evidence of bleeding or severe organ injury diagnosed with contrast-enhanced CT scan.
The decision to perform emergency angiography is determined by discussion between trauma surgeons and radiologists based on CT scan findings and patient status. However, as trauma surgeons are not always present in the hospital, emergency physicians sometimes independently decide emergency angiography.

\section{Study population}

We retrospectively reviewed data from the JTDB between January 2004 and March 2019. Trauma patients who were aged $\geq 18$ years and were transported directly from the scene were included. Patients who arrived with cardiac arrest and those with missing data on the emergency angiography were excluded.

\section{Data collection and definitions}

Available data included age, sex, mechanism of injury, comorbidities, vital signs on hospital arrival, Abbreviated Injury Scale (AIS) score, Injury Severity Score (ISS), presence of compartment syndrome in extremities, vasopressor usage, and any surgical procedures including laparotomy, thoracotomy, resuscitative thoracotomy (RT), and resuscitative endovascular balloon occlusion of the aorta (REBOA). Procedures performed related to traumatic kidney injury such as total nephrectomy, partial nephrectomy, and nephrorrhaphy were also available. The target regions for angiography and concomitant embolization were recorded in the database, but details regarding the indications for angiography or the hemodynamic status during angiography were not available.

Emergency angiography was recorded when an angiography was urgently performed as a hemostatic or diagnostic procedure during the initial resuscitation, regardless of preceding hemostatic surgery or time interval between hospital arrival and initiation of the angiography. Any scheduled or unscheduled angiographic procedures which were conducted after the achievement of initial resuscitation with hemostasis (e.g., angiography for re-bleeding or pseudoaneurysm found later), were not recorded as emergency angiography.

AKI was diagnosed by treating physicians based on a rise in serum creatinine and/or fall in urine output according to any published standard criteria depending on the time of study inclusion. Predefined uniform criteria for AKI were not used in the database. Serum creatine values, urine output, and hemodialysis requirement were not available in the database.

\section{Outcome measures}

The primary outcome was the incidence of AKI prior to discharge. Secondary outcomes included hospital-free days and intensive care unit (ICU)-free days until day 30 . 


\section{Statistical analysis}

Patient data were divided between angiography and nonangiography groups. The angiography group consisted of patients who underwent emergency angiography, while the non-angiography group consisted of those who were treated without emergency angiography. Unadjusted analysis was performed on the primary outcome with Chi-square test.

To select a similar cohort of control patients from the non-angiography group, propensity score matching was performed [17]. The propensity score was developed using a logistic regression model to estimate the probability of being assigned to the angiography group [18]. Relevant covariates were selected from known or possible indications for angiography and background risks for kidney injury, including baseline characteristics such as age, sex, comorbidities, mechanism of injury, vital signs on admission, abdominal AIS, renal AIS, ISS, surgical procedures, and the type of surgery on the kidney $[9,10,13-15,19]$. Patients with missing covariates were excluded from propensity score calculation. The precision of discrimination of propensity score was analyzed with the c-statistic. One-to-one propensity score matching was then performed using a greedy matching algorithm without replacement, where a caliper width of less than 0.2 of the standard deviation of logit-transformed propensity score was applied. Equality of patient characteristics between both groups after matching was evaluated with the standardized difference of each covariate, in which standardized difference $<0.1$ was considered as non-biased distribution $[18,20]$. The inter-group comparison of primary and secondary outcomes after propensity score matching was performed using Chi-square tests or ordinal regression analysis, as appropriate.

An inverse probability weighting analysis using propensity score and a logistic regression analysis with propensity score as covariate were conducted as sensitivity analyses on the whole population $[17,21]$. Furthermore, the primary outcome was compared between the angiography and non-angiography groups in the subgroup of patients who were divided based on the presence of chronic kidney disease (CKD) before injury, age $(\geq 65$ vs $<65$ years), severity of injury (ISS $\geq 25$ vs $<25$ ), vasopressor usage, and the year of injury (2004-2009 vs 2010-2019).

Descriptive statistics are presented as the median (interquartile range) or number (percentage). Results are shown using standardized difference and $95 \%$ confidence interval (CI). Missing/ambiguous values were used without manipulation. Testing of the hypothesis was only performed on the primary outcome, in which a 2-sided $\alpha$ threshold of 0.05 was considered statistically significant. All statistical analyses were conducted using SPSS, version 26.0 (IBM, Armonk, NY), and Microsoft Excel (Microsoft, Redmond, WA).

\section{Results}

\section{Patient characteristics}

Among 361,706 trauma patients in the database, 331,709 adult patients were transported directly from the scene, and 230,776 patients were eligible for this study (Fig. 1). A total of $14,180(6.1 \%)$ patients underwent an emergency angiography.

Patient characteristics are summarized in Table 1. Patients in the angiography group were younger and had lower Glasgow Coma Scale (GCS) and lower systolic blood pressures (sBP) on arrival compared with those in the non-angiography group, as well as higher ISS ( 25 [16-35] vs. 10 [9-18]). Furthermore, more patients in the angiography group underwent surgical procedures than those in the non-angiography group, including total nephrectomy (43 [0.3\%] vs. $100[0.0 \%])$. Vasopressors were used more in the angiography group than in the non-angiography group. Target regions for emergency angiography are shown in Table 2 . The abdomen/pelvis was the major site for angiography $(10,624[83.5 \%])$, and embolization was performed in 5,541 (43.5\%) patients.

The propensity model was validated with 0.818 of c-statistic. Among the 14,180 patients in the angiography group, 12,724 patients were matched with controls in the non-angiography group. Patient characteristics after matching are summarized in Table 1 . In the matched population, background characteristics of patients in the two groups became comparable (standardized differences were $<0.1$ in all covariates after matching).

\section{Incidence of AKI and secondary outcomes}

Unadjusted analysis identified that the incidence of AKI was significantly higher among patients who underwent emergency angiography compared to those who did not (160 [1.1\%] vs. 537 [0.2\%]; odds ratio [OR], 4.59; 95\% confidence interval $[\mathrm{CI}], 3.85-5.48 ; p<0.001$; Table 3 ), and propensity score matching analysis revealed similar results (140 [1.1\%] vs. 67 [0.5\%]; OR, 2.10; 95\% CI, $1.57-$ 2.82; $p<0.001$; Table 3). Hospital-free days and ICU-free days to day 30 were also shorter in patient in the angiography group than in those in the non-angiography group (2 [0-17] vs. 10 [0-22] days; difference in median, 0 [95\% CI, 0-0] days; and 16 [0-25] vs. 20 [7-27] days; difference in median, 2 [95\% CI, 1-2] days, respectively, Table 3).

Inverse probability weighting analysis confirmed that the emergency angiography was associated with the higher incident of subsequent AKI (OR, 1.48; 95\% CI, 1.32-1.67; Additional file 1: Table S1), and logistic regression with propensity score as a covariate identified the 


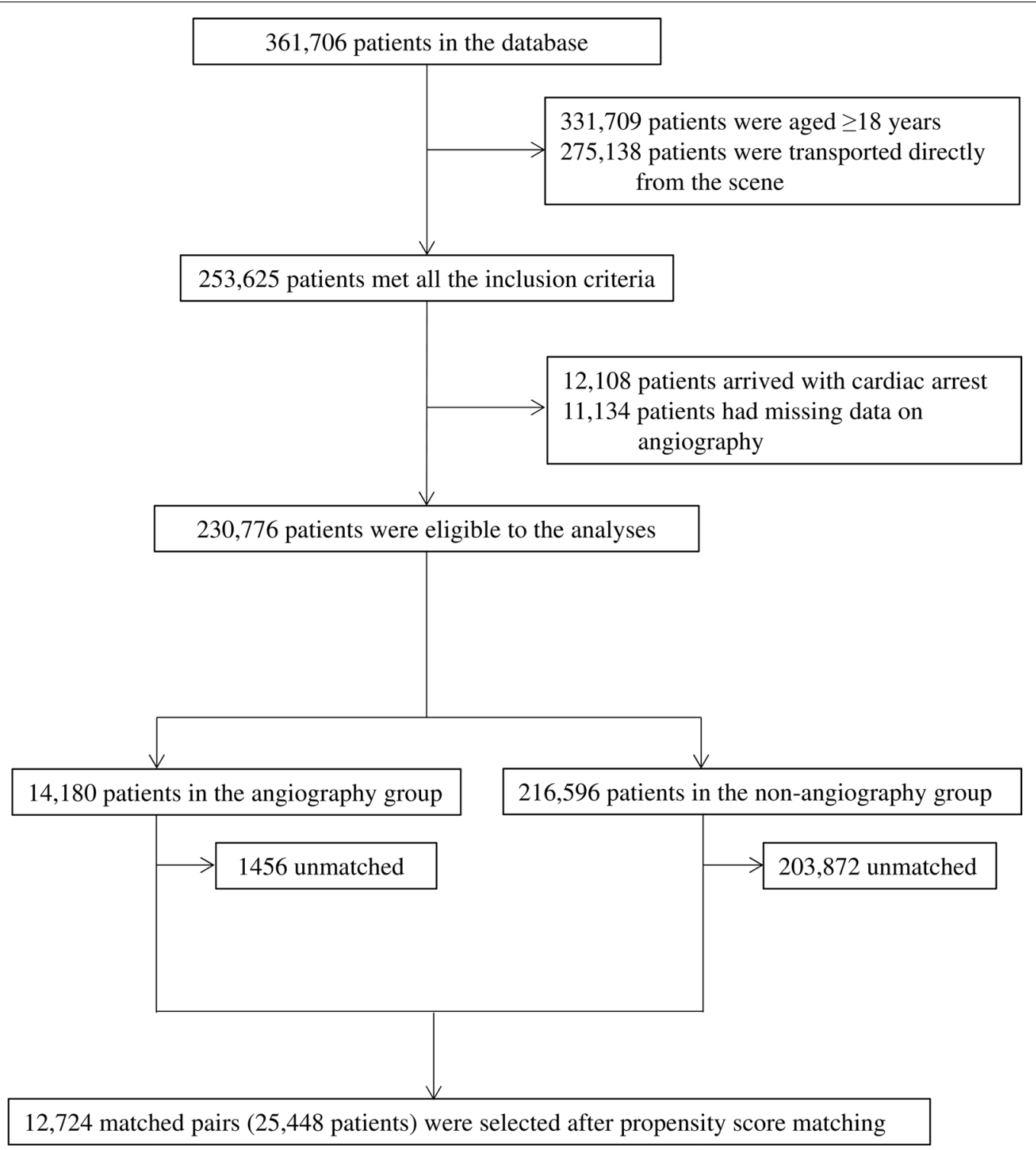

Fig. 1 Patient flow diagram. Among 361,706 trauma patients in the database, 331,709 adult patients were transported directly from the scene, and 230,776 patients were eligible for this study. A total of 14,180 (6.1\%) patients underwent an emergency angiography. Among the 14,180 patients in the angiography group, 12,724 patients were matched with controls in the non-angiography group

similar results (OR, 2.38; 95\% CI, 1.86-3.04; Additional file 1: Table S1).

\section{Subgroup analysis}

In the subgroup analyses (Table 4), the relationship between higher incidence of subsequent AKI and emergency angiography was observed in several subgroups: severe and mild/moderate injury, resuscitation with and without vasopressors, and early and late period of injury during the study period.
Conversely, patients who had CKD before injury had comparable incidence of AKI regardless of emergency angiography, whereas those without history of CKD developed AKI more frequently when they underwent emergency angiography (OR, 2.13; 95\% CI, 1.58-2.86).

Furthermore, emergency angiography was associated with increased subsequent AKI among relatively younger patients who were aged $<65$ years $(\mathrm{OR}, 2.64 ; 95 \% \mathrm{CI}$, 1.82-3.84), whereas the incidence of AKI was comparable between the angiography and non-angiography groups among those who were aged $\geq 65$ years. 


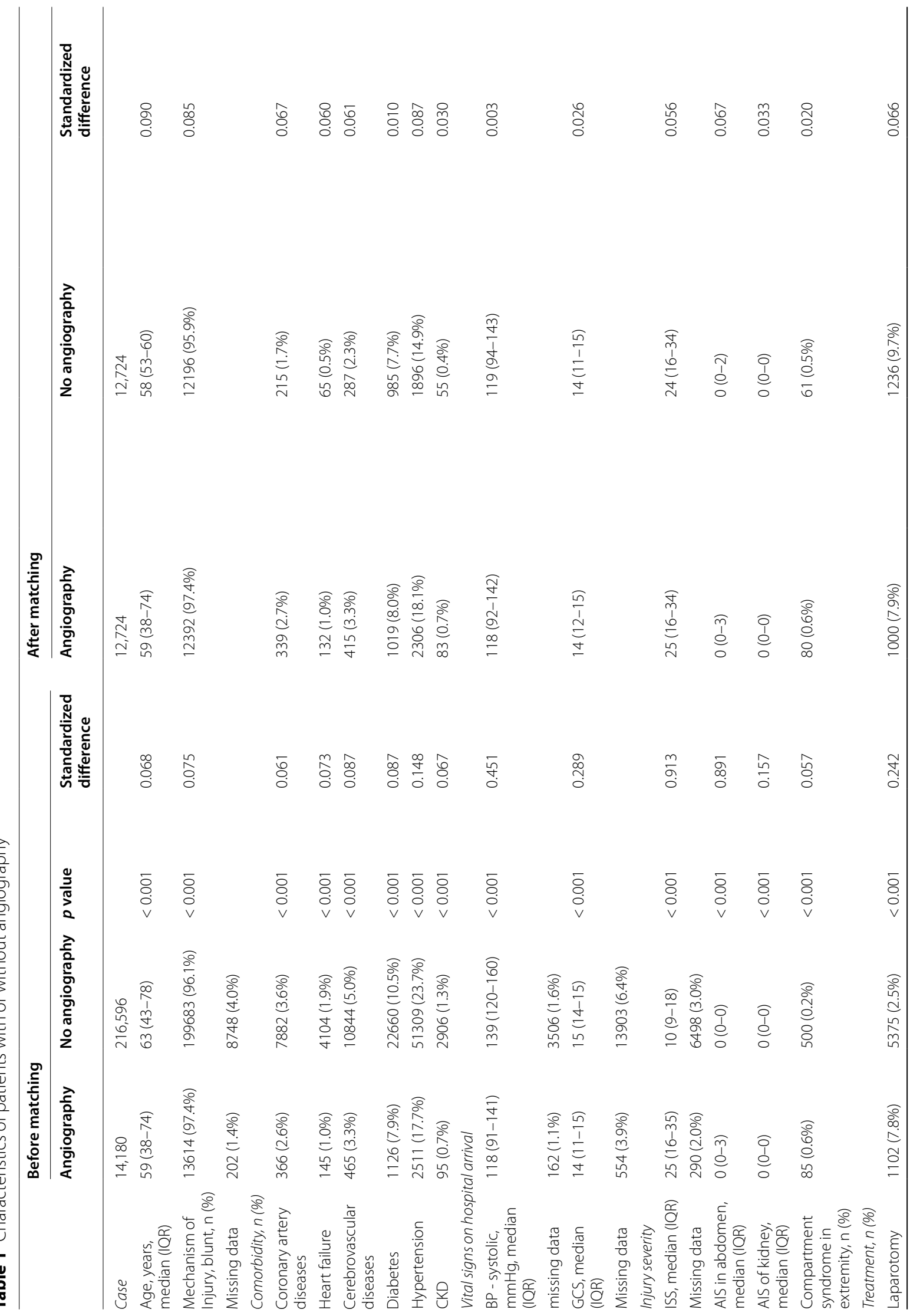




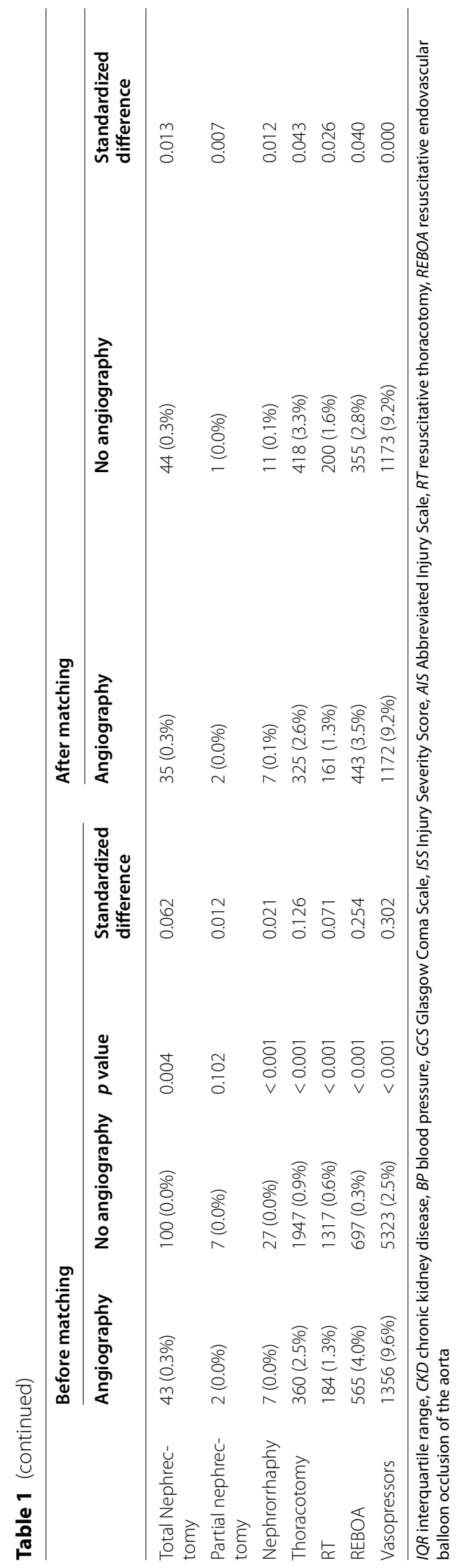


Table 2 Details of angiography

\begin{tabular}{ll}
\hline Body region*, $n(\%)$ & $2411(18.9 \%)$ \\
Head/neck & $3126(24.6 \%)$ \\
Chest & $10,624(83.5 \%)$ \\
Abdomen/pelvis & $1356(10.7 \%)$ \\
Others & $5541(43.5 \%)$ \\
Embolization & \\
\hline
\end{tabular}

${ }^{*}$ Cases were double counted when angiography was conducted across more than two body regions

\section{Discussion}

In this retrospective study, emergency angiography was associated with higher incidence of subsequent AKI. This relationship was validated even after several background risks for kidney injury and injury severity were adjusted. Thus, a future prospective study using predefined criteria for AKI is expected to be conducted for the validation of the current study.

Several pathophysiological mechanisms could be considered for the results in this study. First, the accumulated dose of contrast media is likely similar to the dosage used for coronary angiography (about 200 to $300 \mathrm{ml}$ ), and this amount of contrast is validated as a major risk factor for PC-AKI [22, 23]. During emergency angiography, radiologists usually use low-dose contrast (100 to $150 \mathrm{ml}$ ) [13] in an effort to avoid PC-AKI [22, 24]; however, most trauma patients would have undergone CT scan prior to angiography $[25,26]$ and received an additional 50 to $120 \mathrm{ml}$ of contrast [13, 27]. Second, trauma victims who needed emergency angiography are bleeding, subsequently reducing intravascular volume. As decreased blood flow in the renal arteries precipitates kidney injury [10], the addition of contrast presents an increased risk of nephrotoxicity. Third, systemic inflammation following severe injury affects the tolerance for kidney insult by contrast media. Given that increased acute inflammation is associated with increased risk of PC-AKI [28], background risks of AKI would be high among patients in this study.
In the subgroup analyses, patients with a history of CKD did not have higher incidence of AKI after exposure to the contrast media, which is different from previous studies [29, 30]. One of the possibilities would be potential differences in procedures of angiography between patients with and without CKD. In Japan, standard practice by radiologists in the setting of CKD is to utilize alternative contrast agents [31, 32], and therefore in these cases radiologists would have used less-nephrotoxic agent such as carbon dioxide, instead of contrast media, when baseline kidney function was severely compromised. It should be also emphasized that the 95\% CI of OR for developing AKI was wide (0.16-6.15) and including more patients with CKD would possibly reach a different result. Moreover, the length of hospital stay (LOS) was comparable between the angiography and non-angiography groups, although past studies suggested that PC-AKI was associated with prolonged hospital stay [33]. Considering that the incidence of subsequent AKI was rare in this study, the small number of patients with AKI might not have significantly affected LOS in all the patients. Notably, the length of ventilator usage was longer by 1-2 days in patients treated with the angiography.

Some potential preventions for PC-AKI can be considered if emergency angiography is validated as an independent risk for PC-AKI by a future study. Given that preprocedural hydration with saline or bicarbonate has been shown to prevent PC-AKI [34-36], restoration of intravascular volume should be achieved before

Table 3 Angiography and clinical outcomes

\begin{tabular}{llllll}
\hline & Angiography & No angiography & $\boldsymbol{p}$ value & OR (95\% Cl) & $\begin{array}{c}\text { Difference } \\
\text { in median } \\
\mathbf{( 9 5 \% ~ C l )}\end{array}$ \\
\hline AKI & & & & & \\
$\quad$ Unadjusted, $n(\%)$ & $160(1.1 \%)$ & $537(0.2 \%)$ & $<0.001$ & 4.59 & $(3.85-5.48)$ \\
PS matching, $n(\%)$ & $140(1.1 \%)$ & $67(0.5 \%)$ & $<0.001$ & 2.10 & $(1.57-2.82)$ \\
Hospital-free days to day 30, days, median (IQR) & $2(0-17)$ & $10(0-22)$ & & 0 & $(0-0)$ \\
ICU-free days to day 30, days, median (IQR) & $16(0-25)$ & $20(7-27)$ & & $(1-2)$ \\
\hline
\end{tabular}

$O R$ odds ratio, $C l$ confidence interval, $A K I$ acute kidney injury, $P S$ propensity score, $I Q R$ interquartile range, $I C U$ intensive care unit 
Table 4 In-hospital mortality in subgroup analyses

\begin{tabular}{|c|c|c|c|c|}
\hline & Angiography & No angiography & OR & $95 \% \mathrm{Cl}$ \\
\hline \multicolumn{5}{|l|}{ Development of AKI } \\
\hline with CKD & $3.6 \%(0.0 \%-0.7 \%)$ & $8.8 \%(0.0 \%-0.8 \%)$ & 0.99 & $0.16-6.15$ \\
\hline without CKD & $1.1 \%(0.9 \%-1.3 \%)$ & $0.5 \%(0.4 \%-0.6 \%)$ & 2.13 & $1.58-2.86$ \\
\hline Severe injury (ISS $\geq 25)$ & $1.7 \%(1.4 \%-2.0 \%)$ & $0.8 \%(0.6 \%-1.0 \%)$ & 2.01 & $1.44-2.80$ \\
\hline Mild/moderate injury $($ ISS < 25) & $0.5 \%(0.3 \%-0.7 \%)$ & $0.2 \%(0.1 \%-0.3 \%)$ & 2.23 & $1.21-4.12$ \\
\hline Treated with vasopressors & $4.4 \%(3.2 \%-5.6 \%)$ & $2.0 \%(1.2 \%-2.8 \%)$ & 2.18 & $1.33-3.56$ \\
\hline Treated without vasopressors & $0.8 \%(0.6 \%-1.0 \%)$ & $0.4 \%(0.3 \%-0.5 \%)$ & 2.08 & $1.44-2.99$ \\
\hline Older (age $\geq 65$ years) & $1.2 \%(0.9 \%-1.5 \%)$ & $1.3 \%(0.8 \%-1.8 \%)$ & 0.91 & $0.57-1.46$ \\
\hline Younger (age < 65 years) & $1.0 \%(0.8 \%-1.2 \%)$ & $0.4 \%(0.3 \%-0.5 \%)$ & 2.64 & $1.82-3.84$ \\
\hline Early period (2004-2009) & $1.7 \%(1.1 \%-2.3 \%)$ & $0.4 \%(0.2 \%-0.6 \%)$ & 4.25 & $2.46-7.32$ \\
\hline Late period (2010-2018) & $1.0 \%(0.8 \%-1.2 \%)$ & $0.6 \%(0.4 \%-0.8 \%)$ & 1.61 & $1.14-2.28$ \\
\hline
\end{tabular}

$O R$ odds ratio, $C I$ confidence interval, $A K I$ acute kidney injury, CKD chronic kidney disease, ISS Injury Severity Scale

emergency angiography. As anti-inflammatory medications, such as statins, have shown promising results for the prevention of PC-AKI in clinical studies on coronary angiography [37], this potential treatment should be investigated as an adjunct in trauma patients who require an angiography. Urine alkalization is scheduled to be investigated in an upcoming randomized controlled trial and may become an option for PC-AKI prevention in the near future [38]. To define clinical benefits of such managements, the results in the current study should be further validated in prospective studies using uniform criteria for the diagnosis of AKI.

The results in this study must be interpreted within the context of the study design. We investigated data using the JTDB, which does not record details of emergency angiography, including the indication for the procedure. Thus, our results could have been different if the decision for emergency angiography had been dependent on unrecorded strong prognostic factors for AKI. Another limitation is that serum creatinine, urine output, and hemodialysis requirement were not available in the database. Although AKI was diagnosed and recorded by treating physicians according to published clinical criteria, the specific criteria used for AKI definition and/ or the degree of AKI severity could not be evaluated in this study: As this is a significant limitation, a future prospective study must be conducted to validate the current results. Moreover, we defined the primary outcome as AKI that was subsequently developed after emergency angiography, regardless of the timing of the diagnosis. As CIN, CI-AKI, and PC-AKI are usually defined as newly developed or worsened kidney dysfunction within 2-3 days after the exposure to contrast media [9], our results would be different if such standard definitions are used. However, as no changes in serum creatinine and/ or urine output within a few days would not deny the possibility of gradually deteriorating kidney dysfunction [39], examining the incidence of AKI for longer period would be more clinically relevant. Finally, we investigated only emergency angiographies that were urgently performed during the initial resuscitation. Therefore, the results in this study should not be applied to scheduled angiography, such as one performed for a pseudoaneurysm found later during the hospital course.

\section{Conclusions}

Emergency angiography was associated with increased incidence of subsequent AKI among trauma patients. This result should be validated in a future study using predefined criteria for the diagnosis of AKI. Prevention measures for PC-AKI, such as preprocedural hydration, should be considered in the setting of emergency angiography.

\section{Abbreviations \\ AKI: Acute kidney injury; ISS: Injury Severity Scale; CIN: Contrast-induced nephropathy; CI-AKI: Contrast-induced AKI; PC-AKI: Post-contrast AKI; JTDB: Japan Trauma Data Bank; AIS: Abbreviated Injury Scale; ISS: Injury Severity Score; RT: Resuscitative thoracotomy; REBOA: Resuscitative endovascular balloon occlusion of the aorta; ICU: Intensive care unit; CKD: Chronic kidney disease; CI: Confidence interval; GCS: Glasgow Coma Scale; SBP: Systolic blood pressures; OR: Odds ratio.}

\section{Supplementary Information}

The online version contains supplementary material available at https://doi. org/10.1186/s13017-021-00400-0.

Additional file 1: Table S1. Development of AKI in sensitivity analyses.

\section{Acknowledgements}

None.

\section{Authors' contributions}

RY, RC, JY, and JS contributed to the acquisition of data, conceived and designed the study, interpreted the data, drafted the manuscript, and revised 
the manuscript for important intellectual content. KM contributed to the acquisition of data, interpreted the data, and revised the manuscript for important intellectual content. All authors reviewed and discussed the manuscript. All authors read and approved the final manuscript.

\section{Funding}

There is no financial support in this study.

\section{Availability of data and materials}

The data of this study are available from the Japanese Association for Trauma Surgery and the Japanese Association for Acute Medicine; however, restrictions apply to the availability of these data, which were used under the license for the current study and so are not publicly available. However, data are available from the authors upon reasonable request and with permission of the Japanese Association for Trauma Surgery and the Japanese Association for Acute Medicine.

\section{Declarations}

\section{Ethics approval and consent to participate}

All collaborating hospitals obtained approval of their individual institutional review board (IRB) for conducting research with human participants (approval number 20090087 from the Keio University School of Medicine Keio, Institute of the corresponding author).

\section{Consent for publication}

Not applicable.

\section{Competing interests}

The authors have no relevant conflicts of interest to disclose.

\section{Author details}

${ }^{1}$ Trauma Service/Department of Emergency and Critical Care Medicine, Keio University School of Medicine, 35 Shinanomachi, Shinjuku, Tokyo 160-8582, Japan. ${ }^{2}$ Department of Surgery, UT Health San Antonio, San Antonio, TX, USA.

Received: 22 August 2021 Accepted: 23 October 2021

Published online: 04 November 2021

\section{References}

1. Matsushima K, Hogen R, Piccinini A, Biswas S, Khor D, Delapena S, et al. Adjunctive use of hepatic angioembolization following hemorrhage control laparotomy. J Trauma Acute Care Surg. 2020;88(5):636-43.

2. Zarzaur BL, Kozar R, Myers JG, Claridge JA, Scalea TM, Neideen TA, et al. The splenic injury outcomes trial: an American Association for the Surgery of Trauma multi-institutional study. J Trauma Acute Care Surg. 2015;79(3):335-42.

3. Sabe AA, Claridge JA, Rosenblum DI, Lie K, Malangoni MA. The effects of splenic artery embolization on nonoperative management of blunt splenic injury: a 16-year experience. J Trauma Acute Care Surg. 2009;67(3):565-72.

4. Shapiro M, McDonald AA, Knight D, Johannigman JA, Cuschieri J. The role of repeat angiography in the management of pelvic fractures. J Trauma Acute Care Surg. 2005;58(2):227-31.

5. Miller PR, Chang MC, Hoth JJ, Mowery NT, Hildreth AN, Martin RS, et al. Prospective trial of angiography and embolization for all grade III to $\mathrm{V}$ blunt splenic injuries: nonoperative management success rate is significantly improved. J Am Coll Surg. 2014;218(4):644-8.

6. Virdis F, Reccia I, Di Saverio S, Tugnoli G, Kwan SH, Kumar J, et al. Clinical outcomes of primary arterial embolization in severe hepatic trauma: a systematic review. Diagn Interv Imaging. 2019;100(2):65-75.

7. Dabbs DN, Stein DM, Scalea TM. Major hepatic necrosis: a common complication after angioembolization for treatment of high-grade liver injuries. J Trauma Acute Care Surg. 2009;66(3):621-9.

8. van der Vlies $\mathrm{CH}$, Saltzherr TP, Reekers JA, Ponsen KJ, van Delden OM, Goslings JC. Failure rate and complications of angiography and embolization for abdominal and pelvic trauma. J Trauma Acute Care Surg. 2012;73(5):1208-12.
9. Ostermann M, Joannidis M. Acute kidney injury 2016: diagnosis and diagnostic workup. Critical Care. 2016;20(1).

10. van der Molen AJ, Reimer P, Dekkers IA, Bongartz G, Bellin MF, Bertolotto $M$, et al. Post-contrast acute kidney injury. Part 2: risk stratification, role of hydration and other prophylactic measures, patients taking metformin and chronic dialysis patients: Recommendations for updated ESUR Contrast Medium Safety Committee guidelines. Eur Radiol. 2018;28(7):2856-69.

11. Tsai TT, Patel UD, Chang TI, Kennedy KF, Masoudi FA, Matheny ME, et al. Contemporary incidence, predictors, and outcomes of acute kidney injury in patients undergoing percutaneous coronary interventions: insights from the NCDR Cath-PCI registry. JACC Cardiovasc Interv. 2014;7(1):1-9.

12. Aycock RD, Westafer LM, Boxen JL, Majlesi N, Schoenfeld EM, Bannuru RR. Acute kidney injury after computed tomography: a meta-analysis. Ann Emerg Med. 2018;71(1):44-53.e4.

13. Hsieh TM, Tsai TH, Liu YW, Hsieh CH. Risk factors for contrast-induced nephropathy and their association with mortality in patients with blunt splenic injuries. Int J Surg. 2016;35:69-75.

14. Haines RW, Fowler AJ, Kirwan CJ, Prowle JR. The incidence and associations of acute kidney injury in trauma patients admitted to critical care: a systematic review and meta-analysis. J Trauma Acute Care Surg. 2019;86(1):141-7.

15. Hatton GE, Wang YW, Isbell KD, Finkel KW, Kao LS, Wade CE. Urinary cell cycle arrest proteins urinary tissue inhibitor of metalloprotease 2 and insulin-like growth factor binding protein 7 predict acute kidney injury after severe trauma: a prospective observational study. J Trauma Acute Care Surg. 2020;89(4):761-7.

16. Yamamoto R, Cestero RF, Muir MT, Jenkins DH, Eastridge BJ, Funabiki $T$, et al. Delays in surgical intervention and temporary hemostasis using resuscitative endovascular balloon occlusion of the aorta (REBOA): influence of time to operating room on mortality. Am J Surg. 2020;220(6):1485-91.

17. Austin PC. An introduction to propensity score methods for reducing the effects of confounding in observational studies. Multivariate Behav Res. 2011;46(3):399-424.

18. Brookhart MA, Schneeweiss S, Rothman KJ, Glynn RJ, Avorn J, Stürmer T. Variable selection for propensity score models. Am J Epidemiol. 2006;163(12):1149-56.

19. Raux M, Sartorius D, Le Manach Y, David JS, Riou B, Vivien B. What do prehospital trauma scores predict besides mortality? J Trauma. 2011;71(3):754-9.

20. Lunt M. Selecting an appropriate caliper can be essential for achieving good balance with propensity score matching. Am J Epidemiol. 2014;179(2):226-35.

21. Leisman DE. Ten pearls and pitfalls of propensity scores in critical care research: a guide for clinicians and researchers. Crit Care Med. 2019;47(2):176-85.

22. Gurm HS, Dixon SR, Smith DE, Share D, Lalonde T, Greenbaum A, et al. Renal function-based contrast dosing to define safe limits of radiographic contrast media in patients undergoing percutaneous coronary interventions. J Am Coll Cardiol. 2011;58(9):907-14.

23. Zhao N, Chen Z, Zhou Y, Xu Q, Xu Z, Tong W, et al. Effects of a high dose of the contrast medium iodixanol on renal function in patients following percutaneous coronary intervention. Angiology. 2021;72(2):145-52.

24. Werner S, Bez C, Hinterleitner C, Horger M. Incidence of contrast-induced acute kidney injury (Cl-AKI) in high-risk oncology patients undergoing contrast-enhanced $\mathrm{CT}$ with a reduced dose of the iso-osmolar iodinated contrast medium iodixanol. PLoS ONE. 2020;15(5):e0233433.

25. Matsumoto S, Jung K, Smith A, Yamazaki M, Kitano M, Coimbra R. Comparison of trauma outcomes between Japan and the USA using national trauma registries. Trauma Surg Acute Care Open. 2018;3(1):e000247.

26. Tsurukiri J, Ohta S, Mishima S, Homma H, Okumura E, Akamine I, et al. Availability of on-site acute vascular interventional radiology techniques performed by trained acute care specialists: a single-emergency center experience. JTrauma Acute Care Surg. 2017:82(1):126-32.

27. Davenport MS, Khalatbari S, Cohan RH, Dillman JR, Myles JD, Ellis JH. Contrast Material-induced Nephrotoxicity and Intravenous Low-Osmolality lodinated Contrast Material: Risk Stratification by Using Estimated Glomerular Filtration Rate. Radiology. 2013;268(3):719-28. 
28. Toso A, Leoncini M, Maioli M, Tropeano F, Di Vincenzo E, Villani S, et al. Relationship between inflammation and benefits of early high-dose rosuvastatin on contrast-induced nephropathy in patients with acute coronary syndrome: the pathophysiological link in the PRATO-ACS study (Protective Effect of Rosuvastatin and Antiplatelet Therapy on ContrastInduced Nephropathy and Myocardial Damage in Patients With Acute Coronary Syndrome Undergoing Coronary Intervention). JACC Cardiovasc Interv. 2014;7(12):1421-9.

29. Jakobi T, Meyborg M, Freisinger E, Gebauer K, Stella J, Engelbertz C, et al Feasibility and impact of carbon dioxide angiography on acute kidney injury following endovascular interventions in patients with peripheral artery disease and renal impairment. Journal of Nephrology. 2021.

30. Sebastià C, Páez-Carpio A, Guillen E, Paño B, Garcia-Cinca D, Poch E, et al. Oral hydration compared to intravenous hydration in the prevention of post-contrast acute kidney injury in patients with chronic kidney disease stage IIIb: a phase III non-inferiority study (NICIR study). Eur J Radiol. 2021;136:109509.

31. Criado E, Upchurch GR Jr, Young K, Rectenwald JE, Coleman DM, Eliason $J$, et al. Endovascular aortic aneurysm repair with carbon dioxideguided angiography in patients with renal insufficiency. J Vasc Surg. 2012;55(6):1570-5.

32. Hayakawa N, Kodera S, Ohki N, Kanda J. Efficacy and safety of endovascular therapy by diluted contrast digital subtraction angiography in patients with chronic kidney disease. Heart Vessels. 2019;34(11):1740-7.

33. James MT, Samuel SM, Manning MA, Tonelli M, Ghali WA, Faris P, et al. Contrast-induced acute kidney injury and risk of adverse clinical outcomes after coronary angiography: a systematic review and metaanalysis. Circ Cardiovasc Interv. 2013;6(1):37-43.
34. Jurado-Roman A, Hernandez-Hernandez F, Garcia-Tejada J, Granda-Nistal C, Molina J, Velazquez M, et al. Role of hydration in contrast-induced nephropathy in patients who underwent primary percutaneous coronary intervention. Am J Cardiol. 2015;115(9):1174-8.

35. Maioli M, Toso A, Leoncini M, Gallopin M, Tedeschi D, Micheletti C, et al. Sodium bicarbonate versus saline for the prevention of contrast-induced nephropathy in patients with renal dysfunction undergoing coronary angiography or intervention. J Am Coll Cardiol. 2008;52(8):599-604.

36. Maioli M, Toso A, Leoncini M, Micheletti C, Bellandi F. Effects of hydration in contrast-induced acute kidney injury after primary angioplasty: a randomized, controlled trial. Circ Cardiovasc Interv. 2011;4(5):456-62.

37. Kang WC, Kim M, Park SM, Kim B-K, Lee B-K, Kwon HM. Preventive effect of pretreatment with pitavastatin on contrast-induced nephropathy in patients with renal dysfunction undergoing coronary procedure: PRINCIPLE-II Randomized Clinical Trial. J Clin Med. 2020;9(11):3689.

38. Lombardi M, Molisana M, Genovesi E, De Innocentiis C, Limbruno U, Misuraca $L$, et al. PrevenTion of contrast-inducEd nephropAThy with urinE alkalinization: the TEATE study design. J Cardiovasc Med (Hagerstown). 2020;21(1):65-72.

39. Cheng W, Wu X, Liu Q, Wang H-S, Zhang N-Y, Xiao Y-Q, et al. Postcontrast acute kidney injury in a hospitalized population: short-, mid-, and long-term outcome and risk factors for adverse events. Eur Radiol. 2020;30(6):3516-27.

\section{Publisher's Note}

Springer Nature remains neutral with regard to jurisdictional claims in published maps and institutional affiliations.
Ready to submit your research? Choose BMC and benefit from:

- fast, convenient online submission

- thorough peer review by experienced researchers in your field

- rapid publication on acceptance

- support for research data, including large and complex data types

- gold Open Access which fosters wider collaboration and increased citations

- maximum visibility for your research: over $100 \mathrm{M}$ website views per year

At BMC, research is always in progress.

Learn more biomedcentral.com/submissions 